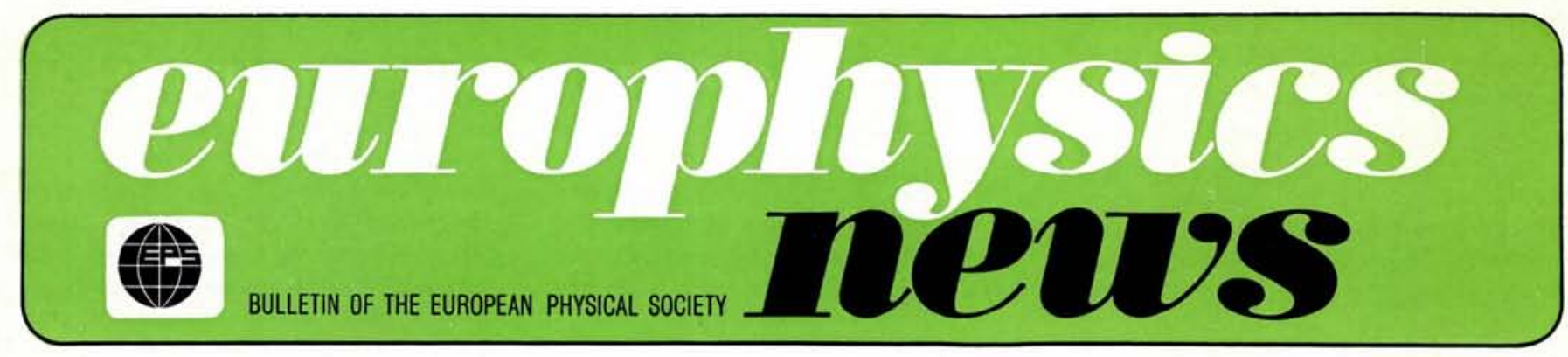

\title{
PHYSICS IN FINLAND
}

K. Eskola, Helsinki

J. Routti, Helsinki

(Helsinki Univ. of Tech., Pres. Finnish Phys. Soc.)

The next meeting of the Council of the European Physical Society will be held in Helsinki March 16 and 17, 1978 preceded by meetings of EPS Committees, March 13-15. Meetings will take place just outside the city of Helsinki in the newly constructed FInnish-Swedish Cultural Centre on the island of Hanasaari.

University traditions in Finland date back to 1640 when the first university was founded in Turku, the capital at that time. Two centuries later it was moved to the new capital Helsinki. The emergence of physics as distinct from natural sciences and its development took place much later.

The Finnish Physical Society which now numbers in its active membership some 600 physicists was founded 30 years ago. There are local chapters of the Society at university towns outside Helsinki and scientific sections in a few fields of intensive research activity.

The programme of the Society concentrates on scientific and professional goals. The Annual General Meeting, attended typically by some 200 members, provides a forum for both scientific reporting and topical discussions of the latest developments in physics. In collaboration with its sister organizations in the exact sciences, the Society publishes a scientific periodical, Arkhimedes. Other activities include symposia and excursions. The Society does not, however, represent its members in negotiations of employment contracts.

Although the Society is a founding member of the European Physical Society, the long distances to other European centres have set some restrictions on its participation, but European contacts have widened in recent years, and it is our hope that the Council meeting in Helsinki will further advance this development.

\section{Physics at Finnish Universities}

Whereas the first chair in physics may be considered as old as the first Finnish university, an explosive increase in investment in physics education and research occurred only after the Second World War. At first, the growth was limited to the physics departments of the existing universities at Helsinki and Turku, but in the 1960's the emphasis on regional development led to the formation of several new universities around the country. As a result, there are now in Finland ten universities with physics departments, three of which are at technical universities with engineering oriented curricula. Such proliferation has opened up a large number of new academic positions for physicists, the total number of professors and associate professors now being about 60 . This development with limited funds, however, has resulted in many small and independent research groups headed by professors who are torn between their teaching, research and administrative roles. Nevertheless, each university has striven to offer a broad physics education to its undergraduates, graduate students and also to aspirants of Ph.D. degree.

University towns with physics departments are shown on the map of Finland, and the fields of active research at each university are indicated in the accompanying table. The classification of the fields of physics is the one used by the journal Physics Abstracts. Being qualitative, it does

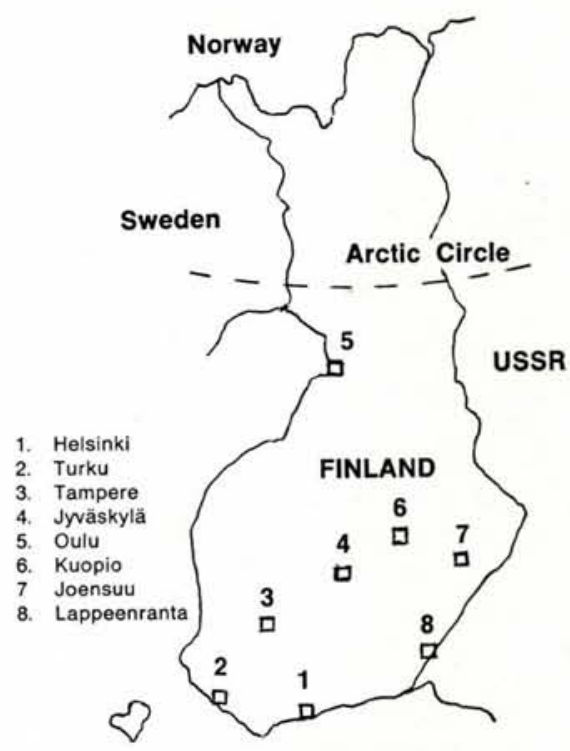

not favour universities with a concentrated effort in one particular field, such as the University of Jyväksylä specializing in nuclear physics.

Physics research at the universities is mainly funded through university budgets. In addition, the National Research Council for Sciences of the Academy of Finland supports special projects, provides grants to doctoral students and funds international collaborations, in particular in high energy physics.

\section{Contents}

Physics in Finland

Doped Amorphous

Semiconductors

RF Supplementary Heating

for Toroidal Reactors.

Non-Linear Optical Resonances and their Applications . . . . 10

Society News

Europhysics News is published monthly by the European Physical Society. (C) 1978. Reproduction rights reserved. 


\section{Research Institutes}

\section{and Major Experimental Facilities}

Unlike many European countries, Finland has not built large physics centres, which in the 1940-50's were set up for military and peaceful applications of nuclear energy. In retrospect, we can consider this as a good choice, for it has given more flexibility in the later development of physics programmes. A few specialized institutes have been formed, typically as extensions to physics projects.

As befitting our northern location, two such laboratories work in low temperature physics. The Low Temperature Laboratory at the Helsinki University of Technology is known for its world record achievements in the search for lowest temperatures. It was also host to the recent 14th International Low Temperature Conference in Helsinki. Solid State Physics, especially at low temperatures, is also studied at the Wihuri Physical Laboratory at the University of Turku.

A Research Institute for Theoretical Physics has been set up at the University of Helsinki to function as a centre of theoretical studies, to aid experimental teams at different universities and to give post-graduate courses.

Several major research facilities in Finland are related to nuclear physics. The oldest one is the $2.5 \mathrm{MeV}$ Van de Graaff accelerator at the University of Helsinki. Associated with it is a Scandinavian type isotope separator and a neutron generator. A new $5 \mathrm{MV}$ EGP-10 Tandem Van de Graaff accelerator has been ordered from the Soviet Union, to be delivered in 1980-81.

Two compact cyclotrons began operating in the middle of the 1970's. The one located in Turku at Åbo
Akademi, which is a variable energy isochronous cyclotron designed at the Research Institute for Electrophysical Apparatus in Leningrad is used mainly for research and education in physics and for the production of radioactive isotopes, mainly for biomedical purposes. The other cyclotron is at the University of Jyväskylä and is a Swedish-made mini-cyclotron Scanditronix MC-20. It is predominantly used for research in low energy nuclear physics. For the present, transitional nuclei and nuclei in the tin and lead regions are of primary interest.

At the Helsinki University of Technology and its adjacent State Research Centre in Otaniemi, a Triga type research reactor has been in operation since 1962. The programme includes neutron physics experiments for materials studies and more routine operations of isotope production, activation analysis, uranium prospecting and tracer studies. A radio telescope with a radome and an antenna of $13.7 \mathrm{~m}$ diameter has been constructed at the same university and is used for radio astronomy and communication studies in the range $3-100 \mathrm{GHz}$.

\section{Scandinavian Collaboration}

Scientific collaboration between the Nordic countries Denmark, Finland, Iceland, Norway and Sweden is based on long traditions and even on formal governmental agreements. Perhaps the best example of joint undertakings in physics is the Nordic Institute for Theoretical Atomic Physics (NORDITA) located in Copenhagen on the same site as the Niels Bohr Institute. Each country sends research fellows and receives guest scientists from Scandinavian and other countries.

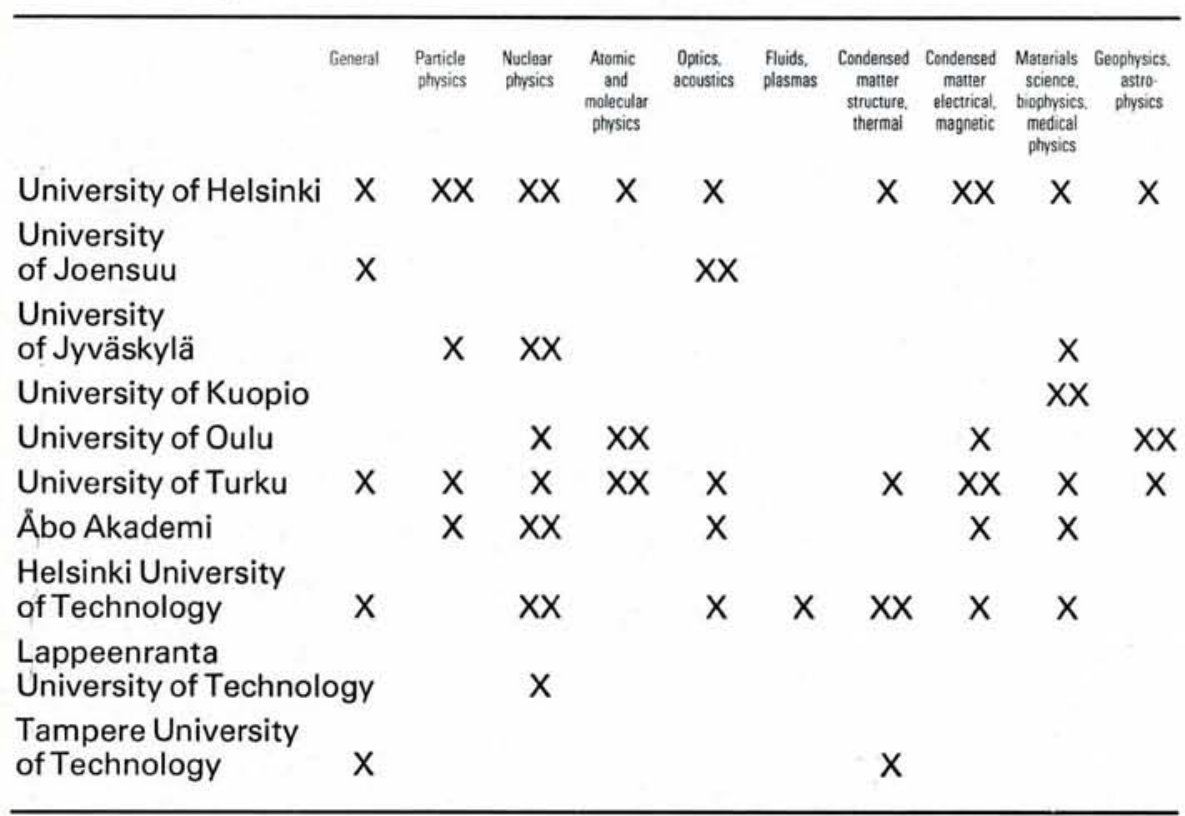

Finnish experimental nuclear physicists have greatly benefitted from cooperation with accelerator laboratories in Scandinavia. Earlier contacts were often based on bilateral arrangements between individual scientists and research teams. However, to encourage such cooperation and to enhance the effective use of the facilities, a Nordic Committe for accelerator-based research has been set up. High energy physicists also actively collaborate with their Scandinavian collegues in analyzing data from experiments carried out jointly at CERN.

The northern location makes Finland a natural base for studies of such geophysical phenomena as the aurora. The European Incoherent Scatter Observatory is being set up as a large scale joint effort of Finland, Norway and Sweden and also of the Federal Republic of Germany, France and the United Kingdom in the form of the EISCAT Scientific Association. All of its three stations are in Scandinavia, with one in Sodankylä above the arctic circle in northern Finland.

Yet another example of Nordic collaboration in physics is the recent agreement by all parties to dicontinue separately publishing national physics journals and instead, jointly publish Physica Scripta, which is already a well established Europhysics Journal.

\section{Association with International Centres}

Although Finland is not a full member of the large European nuclear research centres in CERN and JINR, it has acquired an associate status allowing limited participation. Finnish particle physicists are taking part in experiments carried out at both centres. Much of their effort has concentrated on studies of antiprotonproton interactions above $10 \mathrm{GeV} / \mathrm{c}$ beam momentum at both the CERN and Serpukhov accelerators. Theoretical particle physicists also have many connections with CERN and to a lesser degree also to JINR. Summer schools and symposia have become almost annual attractions.

Contacts with other large research centres inside and outside Europe are many but mostly arranged through individual initiatives. A long series of visits by Finnish nuclear physicists to Lawrence Berkeley Laboratory of the University of California is a good example of such contacts.

\section{Physics in Finnish Industry}

Traditional major industries in Finland are forest industries based on the large natural resources. Paper 
and wood products still account for about one half of the exports. Metal and construction industries have followed in importance. Light industries, such as electronics, have more recently emerged as major contributors to employment and trade.

As a result of the industrial structure, physics has mostly been used in assistive roles, such as instrumentation, process control and quality assurance. On a smaller scale, however, more directly physics related industries have come forward. As examples can be cited the fabrication of meterological radiosondes, medical, environmental monitoring and nuclear instruments. For success in such efforts, international competitiveness has been required, since domestic markets are too small to support them.
The limited domestic energy sources, mostly in the form of hydropower and wood and peat reserves, and the large energy needs of heavy industries and domestic heating have encouraged Finland to seek new energy sources, in particular, extensive use of nuclear power. One pressurized water reactor of $440 \mathrm{MW}$ electric power was successfully put into operation in early 1977 and another is under construction on the southern coast at Loviisa. These reactors have been supplied by the Soviet Union to the state owned power company, which in collaboration with other suppliers has incorporated in the plant design the required containment and safety systems. Two boiling water reactors of $660 \mathrm{MW}$ electric power are in an advanced construction phase on the western coast at Olkiluoto. The units are of Swedish design and will be operated by a company owned by Finnish industries.

The development of nuclear power has benefitted from international collaboration through the International Atomic Energy Agency and the Nuclear Energy Agency of the OECD, as well as through several bilateral and multilateral agreements.

International contacts, whether in academic or applied physics are vital for a prosperous development of physics in a small country like Finland. The contributions of the European Physical Society in advancing such contacts are recognized and we hope that the meeting of the EPS Council in Helsinki will promote these aims on a wider European level.

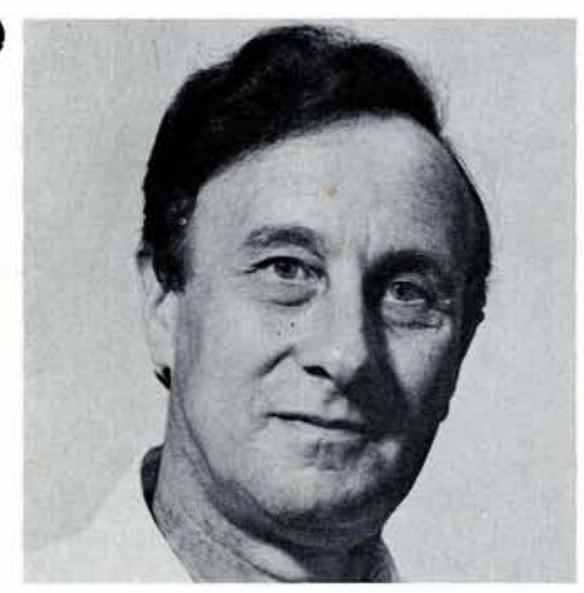

During recent years there has been a rapidly growing interest in the electronic properties of amorphous (a-) solids $\left.{ }^{1}\right)$. These materials have provided the solid state physicist with new and challenging fundamental problems and it is also likely that applications will follow the basic advances that have been made. The elemental a-semiconductors, $\mathrm{Si}$ and $\mathrm{Ge}$, which are the subjects of this article, have played a prominent part in this development. In the following sections I should like to give a brief outline of their preparation and electronic properties and then show how substitutional doping in the a-phase has opened up a wide range of new possibilities for both fundamental studies and device applications of a-semiconductors.

Structurally, a-materials lack the long range order found in the crystalline state, but in $\mathrm{a}-\mathrm{Si}$ and $\mathrm{Ge}$ the short range order is still determined by the well known tetrahedral bonds. $\mathrm{X}$-ray work on these materials has shown that at least some ordering can

\section{Doped Amorphous Semiconductors}

\section{W.E. Spear, Dundee Winner of the EPS 1977 Hewlett-Packard Europhysics Prize}

be found within a few atomic spacings around a given atom; it disappears at larger distances, mainly as a result of fluctuations in the bond angles. This has led to the concept of the "continuous random network" as a structural model characteristic of the a-state.

\section{Preparation of a-Semiconductors}

Probably the most widely used methods for depositing a-semiconductor films are evaporation in a high vacuum and cathodic sputtering. A striking feature of a-Si or a-Ge specimens prepared by these methods is the critical dependence of their electrical and optical properties on the experimental conditions during deposition and on the subsequent annealing treatment. It is now known that this behaviour is caused mainly by defect states in the mobility gap of the a-semiconductor. The random network in evaporated or sputtered specimens is far from continuous - it contains numerous vacancy-like defects which can form clusters of up to
$10 \AA$ across. Unsaturated (or "dangling") bonds at internal surfaces of the voids give rise to electronic states which often dominate the observed properties of the material and also introduce a marked sensitivity to reactive gases.

A basically different approach to preparation, which has played an important role in the development of the subject, has been the deposition of a-semiconductor films from the gas phase by decomposing the hydride in a radio frequency glow discharge. For instance, a-Si specimens are formed in this way from silane gas $\left(\mathrm{SiH}_{4}\right)$, a-Ge from germane, a-C from acetylene, and compounds such as a-SiC can be prepared from suitable gas mixtures. As we shall see, the electronic properties of glow discharge specimens are determined to a much lesser extent by the defect states mentioned above, so that experimental results are more representative of the intrinsic properties of the continuous random network. It is likely that gas phase deposition techniques will find 